\title{
Pebisnis Islam dan Muslim Kelas Menengah ke Atas di Indonesia: Kesalehan, Gaya Hidup, dan Pasar
}

\author{
Dony Arung Triantoro \\ Fakultas Dakwah, UIN Sultan Syarif Kasim Riau, Indonesia \\ (email: arungdony73@gmail.com)
}

\begin{abstract}
The discussion regarding middle and upper class Muslims in Indonesia has become an interesting study among scholars with different focus of study. The reason is because middle and upper class Muslims continue to move dynamically and play an important role in the socio-religious landscape in Indonesia. This paper seeks to explain the global discourse that has initiated the emergence of a new lifestyle among middle and upper class Muslims in Indonesia. The purpose of this study is to analyze the phenomenon that develops both offline and online. Islamic expressions displayed by middle and upper class Muslims in Indonesia show the intersection of piety, lifestyle, and the market. The theory used in this study is the constructivism paradigm, phenomenology, and virtual communication. The method used is a phenomenological approach through observation from 2018 to early 2020, on business actors in Yogyakarta and Pekanbaru. The results of the analysis of this study argue that the increasing expression of Islam among middle and upper class Muslims has in turn initiated the emergence of Islamic business actors who facilitate the new lifestyle of upper middle class Muslims.
\end{abstract}

\section{Keywords:}

Businessman Islam, Muslim, Middle Class and Upper Class, Piety, Lifestyle

\begin{abstract}
Abstrak
Diskusi mengenai Muslim kelas menengah ke atas di Indonesia telah menjadi kajian menarik di kalangan sarjana dengan fokus kajian yang berbeda-beda. Alasannya, karena Muslim kelas menengah ke atas terus bergerak dinamis dan memainkan peran penting dalam lanskap sosial keagamaan di Indonesia. Tulisan ini berupaya menjelaskan wacana global yang menginisiasi munculnya gaya hidup baru di kalangan Muslim kelas menengah ke atas di Indonesia. Tujuan kajian ini adalah menganalisis fenomena yang berkembang baik secara offline maupun online, ekspresi keislaman yang ditampilkan Muslim kelas menengah ke atas di Indonesia menunjukkan persimpangan antara kesalehan, gaya hidup, dan pasar. Teori yang digunakan dalam kajian ini adalah paradigma konstruktivisme, fenomenologi, dan
\end{abstract}


komunikasi virtual.Metode yang digunakan adalah pendekatan fenomenologi melalui observasi sejak tahun 2018 sampai awal 2020, pada para aktor bisnis di Yogyakarta dan Pekanbaru. Hasil analisis kajian ini memberikan argumentasi bahwa meningkatnya ekspresi keislaman di kalangan Muslim kelas menengah ke atas pada gilirannya menginisiasi munculnya para aktor bisnis Islam yang memfasilitasi gaya hidup baru Muslim kelas menengah ke atas.

\section{Kata Kunci:}

Pebisnis Islam, Muslim, Kelas Menengah ke Atas, Kesalehan, Gaya Hidup

\section{Pendahuluan}

Mengikuti pengajian berbayar mahal yang digelar di hotel-hotel mewah, memilih paket ibadah umrah yang dapat sekaligus menikmati keindahan negaranegara di Timur Tengah, memilih untuk tinggal di perumahan Islam, dan mengonsumsi obat-obatan herbal, serta memakai pakaian-pakaian Islam bermerek terkenal merupakan gaya hidup sekaligus praktik keagamaan baru di kalangan Muslim kelas menengah ke atas di Indonesia belakangan ini. Gaya hidup dan praktik keagamaan yang mereka tampilkan berbeda jauh dengan Muslim tradisional pada umumnya. Tulisan ini berupaya menjelaskan ekspresi gaya hidup dan praktik keagamaan di kalangan Muslim kelas menengah ke atas tersebut.

Muslim kelas menengah di Indonesia yang muncul pada tahun 1980-an adalah mereka yang mendapatkan akses pendidikan, menikmati pertumbuhan ekonomi dan akses ke birokrasi di era Orde Baru. ${ }^{1}$ Selain itu, menurut Richard Robison bahwa kelas menengah di Indonesia sangat menggantungkan pekerjaan, karier dan perlindungannya pada birokrasi, sehingga mereka lebih bersifat apolitis atau enggan menyuarakan reformasi birokrasi. ${ }^{2}$ Sikap apolitis ini tetap berjalan hingga Presiden Soeharto diturunkan pada Mei 1998. Perkembangan terakhir tentang sikap politik

${ }^{1}$ Hal Hill, "The Economy," dalam Indonesia's New Order: The Dynamics of Socio-Economic Transformation, ed. oleh Hal Hill (Honolulu: University of Hawaii Press, 1994), 54-122.

2 Richard Robison, "The middle class and the bourgeoisie in Indonesia," dalam The New Rich in Asia: Mobile phones, McDonald's and middle-class revolution, ed. oleh Richard Robison dan David S. G. Goodman (New York: Routledge, 1996), 81.

80 | El Madani: Jurnal Dakwah dan Komunikasi Islam, Volume 1 No. 02 (2020) 
Pebisnis Islam dan Muslim Kelas Menengah ke Atas di Indonesia: Kesalehan, Gaya Hidup, dan Pasar Muslim kelas menengah di Indonesia bergeser dari yang sebelumnya apolitis menjadi politis. ${ }^{3}$

Di samping sikap politisnya, Muslim kelas menengah banyak terlibat dalam proyek-proyek produk keislaman. Inayah Rokhmani mencatat bahwa Muslim kelas menengah ke atas banyak yang mengonsumsi dan bahkan mendirikan televisi komersial atau swasta pasca runtuhnya Soeharto. Mereka memproduksi siaran-siaran Islam seperti azan dan acara dakwah yang diisi oleh para intelektual Muslim seperti Quraish Shihab. ${ }^{4}$

Motif mereka mendirikan televisi komersial tersebut tidak hanya ingin menyebarkan Islam di ruang publik, tetapi pada saat yang bersamaan, mereka menangkap logika pasar televisi. Meningkatnya penonton Muslim pada saat itu memungkinkan mereka mendapatkan keuntungan besar dari siaran-siaran Islam. Ihwal ini sama seperti yang digambarkan oleh Chua Beng Huat dan Tan Ean tentang kemunculan kelas menengah di Singapura. Masyarakat Singapura yang masuk ke dalam kelas menengah ke atas adalah mereka yang mengembangkan logika ekonomi kapitalis dalam mencapai kesejahteraan hidup pribadi maupun kolektif. ${ }^{5}$

Studi mengenai Muslim kelas menengah ke atas di Indonesia telah banyak dilakukan oleh para sarjana. Studi-studi tersebut dapat dilihat dalam karya Ariel Heryanto, Noorhaidi Hasan, dan Nancy J. Smith-Hefner. Dalam menelisik fenomena Muslim kelas menengah ke atas di Indonesia, Heryanto tidak terjebak dalam analisis etnisitas (faktor etnis). Ini sama seperti kajian yang dilakukan Chua Beng Huat dan Tan Joo Ean ketika menjelaskan kemunculan kelas menengah di Singapura. Huat dan Ean dalam studinya tidak menggunakan analisis etnisitas untuk menelisik kemunculan kelas menengah ke atas di Singapura, karena menurut mereka bahwa

${ }^{3}$ Wasisto Raharjo Jati, "Memaknai Kelas Menangah Muslim sebagai Agen Perubahan Sosial Politik Indonesia," At-Tahrir 16, no. 1 (2016): 133-51.

${ }^{4}$ Inaya Rakhmani, Mainstreaming Islam in Indonesia: television, identity, and the middle class (New York, NY: Palgrave Macmillan, 2016), 39.

${ }^{5}$ Chua Beng Huat dan Tan Joo Ean, "Singapore: Where the new middle class sets the standard," dalam Culture and Privilege in Capitalist Asia, ed. oleh Michael Pinches (London and New York: Routledge, 1999), 140. 
meskipun Singapura memiliki garis etnisitas yang beragam seperti Cina, Melayu dan India, tetapi garis etnis tidak menjadi variabel penting yang menyebabkan mereka menjadi miskin ataupun kaya. ${ }^{6}$ Temuan penting dari studi yang dilakukan Heryanto adalah bahwa gaya hidup Muslim kelas menengah ke atas merupakan alat politik identitas mereka, sehingga pada gilirannya menjadi wacana publik, persaingan identitas, dan bahkan wacana pembangunan sosial di Indonesia. ${ }^{7}$

Berbeda dengan Heryanto yang mengaitkan gaya hidup Muslim kelas menengah ke atas dengan politik identitas, studi belakangan yang dilakukan oleh Hasan memiliki signifikansi yang berbeda. Hasan mengaitkan isu Muslim kelas menengah dengan ruang publik Islam. Menurut Hasan bahwa kemunculan Muslim kelas menengah ikut mewarnai wacana Islam publik di Indonesia. Ekspresi keislaman yang ditampilkan oleh Muslim kelas menengah di ruang publik Indonesia tidak hanya menunjukkan identitas kesalehan mereka, tetapi juga menginisiasi munculnya praktik komodifikasi agama yang bersamaan dengan permintaan pasar terhadap produk-produk Islam. ${ }^{8}$

Gaya hidup baru yang ditampilkan oleh Muslim kelas menengah ke atas di Indonesia seperti yang disampaikan Heriyanto dan Hasan di atas tidak selalu berbentuk produk-produk keislaman. Smith-Hefner dalam studinya, misalnya, dia mengkaji tentang bagaimana anak muda Muslim berpendidikan di Jawa memanfaatkan waktu luang mereka untuk berekreasi di pusat-pusat perbelanjaan modern, sehingga pada gilirannya ihwal itu menjadi gaya hidup dan pola konsumsi kelas menengah. Temuan Smith-Hefner menunjukkan bahwa anak muda berpendidikan di Jawa menikmati waktu luang dan pola konsumsinya dengan penuh negosiasi dan tantangan, sehingga Smith-Hefner menyimpulkan bahwa kelas

${ }^{6}$ Huat dan Ean, "Singapore: Where the new middle class sets the standard," 138-59.

7 Ariel Heryanto, "The years of living luxuriously Identity politics of Indonesia's new rich," dalam Culture and Privilege in Capitalist Asia, ed. oleh Michael Pinches (London and New York: Routledge, 1999), 179-80.

${ }^{8}$ Noorhaidi Hasan, "The Making of Public Islam: Piety, Agency, and Commodification on the Landscape of the Indonesian Public Sphere," Contemporary Islam 3, no. 3 (Oktober 2009): 229-50, https://doi.org/10.1007/s11562-009-0096-9.

82 | El Madani: Jurnal Dakwah dan Komunikasi Islam, Volume 1 No. 02 (2020) 
Pebisnis Islam dan Muslim Kelas Menengah ke Atas di Indonesia: Kesalehan, Gaya Hidup, dan Pasar menengah baru di Indonesia tidak hanya terkait tentang aktivitas berbelanja, tren fashion, dan aktivisme sosial lainnya, tetapi juga terkait bagaimana Muslim kelas menengah baru menegosiasikan identitas keislaman mereka dengan simbol-simbol modernitas. ${ }^{9}$

Studi-studi yang ada kurang memberikan perhatian pada wacana global yang mempengaruhi munculnya gaya hidup baru di kalangan Muslim kelas menengah ke atas di Indonesia. Melanjutkan studi-studi sebelumnya tulisan ini berupaya menjelaskan wacana global yang mempengaruhi ekspresi Muslim kelas menengah di Indonesia. Tulisan ini juga berupaya memotret persimpangan antara kesalehan, gaya hidup, dan pasar yang mengelilingi kehidupan Muslim kelas menengah ke atas di Indonesia. Kemudian saya memberikan contoh kasus-kasus terbaru tentang ekspresi Muslim kelas menengah di Indonesia.

Tulisan ini berargumen bahwa kemunculan dan ekspresi gaya hidup Muslim kelas menengah di Indonesia setidaknya dipengaruhi oleh beberapa wacana yang mengelilinginya antara lain wacana globalisasi, program pembangunan (developmentalisme) di era Orde Baru dan semangat gerakan kebangkitan Islam. Selain itu, tulisan ini juga berargumen bahwa meningkatnya ekspresi keislaman di kalangan Muslim kelas menengah ke atas pada gilirannya menginisiasi munculnya para aktor bisnis Islam yang memfasilitasi gaya hidup baru Muslim kelas menengah ke atas. Untuk menjelaskan argumentasi tersebut, tulisan ini dibagi menjadi beberapa bagian. Bagian pertama, saya menjelaskan tentang wacana globalisasi yang memotret pada wacana sekularisasi. Sedangkan pada bagian kedua, saya akan menjelaskan Islam di masa Orde Baru dan terakhir, saya akan menunjukkan tren-tren gaya hidup terkini di kalangan Muslim kelas menengah ke atas di Indonesia.

${ }^{9}$ Nancy J. Smith-Hefner, "Satan in the Mall: Leisure and Consumption in Java's New Muslim Middle Class," dalam Testing the Margins of Leisure Case Studies on China, Japan, and Indonesia, ed. oleh Rudolf G Wagner dkk. (German: Heidelberg University Publishing, 2020), 153-80, https://doi.org/10.17885/heiup.550. 


\section{Kajian Pustaka}

Kajian ini didasarkan pada penelitian terdahulu dari Asmaul Husna yang berjudul "Komodifikasi Agama: Pergeseran Praktik Bisnis dan Kemunculan Kelas Menengah Muslim" yang mengangkat masalah tentang euforia aktualisasi identitas religius dimanfaatkan oleh para pelaku bisnis untuk dijadikan komoditas yang kemudian dijadikan sebagai alat jual. Penelitian dengan studi pustaka ini menghasilkan simpulan bahwa perbedaan religiusitas dan bisnis menjadi kabur; praktik keagamaan mulai terjebak dalam kerangka simbolik yang hanya mengutamakan kamuflase dan pencitraan belaka. ${ }^{10}$ Selain itu dari Wasisto Raharjo Jati dengan judul "Islam Populer sebagai Pencarian Identitas Muslim Kelas Menengah Indonesia" yang menganalisis konstruksi identitas dalam studi kasus Muslim Kelas Menengah di Indonesia. Simpulannya bahwa citra yang ditampilkan pada saat mengonsumsi produk menciptakan konstruksi Kelas Menengah Islam, Kelas Menengah yang religius, dan Kelas Menengah Arab. ${ }^{11}$

\section{Kerangka Teoretis}

Kajian ini menggunakan teori konstruktivisme dalam melihat dunia yang dibangun pebisnis Islam kelas menengah ke atas, juga fenomenologi dalam memahami dan memaknai wacana pelaku bisnis kelas menengah ke atas. Selain itu, teori komunikasi virtual dalam mengeksplorasi keterlibatan internet dalam memfasilitasi wacana pada pelaku bisnis tersebut.

${ }^{10}$ Asmaul Husna, “Komodifikasi Agama: Pergeseran Praktik Bisnis dan Kemunculan Kelas Menengah Muslim," Jurnal Komunikasi Global 7, no. 2 (2018): 227-39.

${ }_{11}$ Wasisto Raharjo Jati, Islam Populer sebagai Pencarian Identitas Muslim Kelas Menengah Indonesia", Jurnal Tasawuf dan Pemikiran Islam, (October 2015), Vol. 5(1):139. 


\section{Metode Penelitian}

Secara metodologis, artikel ini menggunakan pendekatan fenomenologi. Fenomena-fenomena terkait topik artikel ini telah saya amati (observasi) sejak tahun 2018 sampai awal 2020 baik secara langsung maupun melalui media internet. Dalam rentang waktu tersebut saya banyak mengamati fenomena terkait topik artikel ini di dua kota yaitu Yogyakarta dan Pekanbaru. Saat di Yogyakarta, saya banyak mengamati aktor bisnis Islam yang menyediakan ruang bagi Muslim kelas menengah ke atas untuk mengekspresikan gaya hidup keislaman mereka. Begitu juga di Pekanbaru, saya mengamati hal yang sama dan bahkan memakai dan menikmati produk-produk Islam itu secara langsung. Selain itu, saya juga mengamati fenomena ini melalui media internet baik berupa sumber pemberitaan online, maupun media sosial. Hasil pengamatan-pengamatan ini kemudian saya deskripsikan, analisis, dan diskusikan dengan literatur-literatur terdahulu yang memiliki fokus penelitian yang sama.

\section{Hasil Penelitian dan Pembahasan}

\section{Wacana Sekularisasi dan Islam di Indonesia}

Fenomena yang sangat mengemuka di dunia barat pada tahun 60-an adalah sekularisasi. Dalam pandangan politik, sekularisasi diartikan pemisahan agama dari perhatian negara. Singkatnya, agama menjadi hajat pribadi pemeluknya (privatisasi) bukan ihwal yang dibincangkan di ruang publik. ${ }^{12}$ Namun, pertanyaan yang kemudian perlu ditelisik kembali adalah apakah agama benar-benar hilang dari ruang publik ataukah agama menjelma dalam bentuk-bentuk lainnya. Untuk menjawab pertanyaan ini, para sarjana sosial terfragmentasi menjadi dua pandangan besar. Bryan Wilson (lihat juga Max Weber, Emile Durkheim, Peter L. Berger), misalnya, berpandangan bahwa tesis sekularisasi benar-benar terbukti dan pada gilirannya agama menjadi hilang dari perbincangan publik akibat modernisasi.

${ }^{12}$ Jose Casanova, “The Secular and Secularisms," social research 76, no. 4 (2009): 1049-66. 
Singkatnya, dia berpandangan bahwa semakin modern masyarakat maka agama akan kehilangan popularitasnya. ${ }^{13}$

Dalam teori sosiologi, ihwal di atas oleh sarjana seperti Pippa Norris dan Ronald Inglehart disebut dengan istilah existensial security theory (teori jaminan keamanan). Norris dan Inglehart berargumen bahwa semakin masyarakat terjamin keamanannya, mapan ekonominya, terjamin kebutuhan hidupnya, akses layanan kesehatan yang mudah, dan sumber informasi yang terjangkau, maka ia akan meninggalkan agama. Begitu pula sebaliknya, agama cenderung mendapatkan tempat di kalangan masyarakat yang tingkat jaminan keamanannya lemah. Masyarakat tradisional (miskin), misalnya, mereka tidak memiliki penghasilan yang mencukupi, sulitnya mendapatkan akses informasi publik, terbatasnya akses kesehatan, makanan dan minuman. Singkatnya, mereka berada pada tingkat kecemasan yang mendalam. Pada kondisi seperti itu, maka agama menjadi satusatunya harapan bagi mereka yang akan membantu menyelesaikan kesulitan hidupnya. ${ }^{14}$ Oleh karena itu, agama menjadi relevan di kalangan mereka. Hal senada juga didengungkan oleh Bronislaw Malinowski yang mengatakan bahwa ritual keagamaan merupakan cara untuk mengatasi kecemasan dan ketidakpastian bagi penganutnya. $^{15}$

Berbeda dengan Wilson yang meyakini bahwa teori sekularisasi benar-benar terbukti, sarjana lainnya seperti Jose Casanova, misalnya, dia berpandangan bahwa tesis sekularisasi tidak sepenuhnya terbukti. Dengan melihat kasus Televangelisme di Amerika Serikat, Jery Falwell sangat mengemuka di ruang publik Amerika untuk mempromosikan ajaran Moral Majority yang kemudian oleh Susan Harding dalam studinya menyebutkan bahwa ajaran moral majority berubah menjadi Southern

${ }^{13}$ Bryan R. Wilson, Religion in secular society: fifty years on, ed. oleh Bruce, Reissue edition (Oxford, United Kingdom: Oxford University Press, 2016), 44-58.

14 Pippa Norris dan Ronald Inglehart, Sacred and secular: religion and politics worldwide, 2nd ed, Cambridge studies in social theory, religion and politics (Cambridge: Cambridge University Press, 2011), 13-17.

15 Heidi Campbell, ed., Digital religion: understanding religious practice in new media worlds (Abingdon, Oxon ; New York: Routledge, 2012), 26.

86 | El Madani: Jurnal Dakwah dan Komunikasi Islam, Volume 1 No. 02 (2020) 
Pebisnis Islam dan Muslim Kelas Menengah ke Atas di Indonesia: Kesalehan, Gaya Hidup, dan Pasar Baptist. Munculnya Jery Falwell menunjukkan bahwa tesis sekularisasi tidak terbukti dan pada gilirannya agama mengalami deprivatisasi. ${ }^{16}$

Selain itu, Casanova melihat bahwa para pendukung teori sekularisasi selalu mengambil kasus pada masyarakat Eropa yang tengah mengalami ekspansi industrialisasi besar-besaran sehingga mereka hanya sedikit mengambil peran dalam institusi gereja. Para pendukung sekularisasi menganggap bahwa apa yang terjadi di Eropa merupakan tren universal, padahal di negara-negara lain mempunyai ciri yang khas dan berbeda dengan apa yang terjadi di Eropa. ${ }^{17}$

Perdebatan seru tentang sekularisasi tidak berhenti sampai di situ saja, Bryan S. Turner dalam studinya mengatakan bahwa sekularisasi benar-benar terbukti. Dia mengatakan bahwa pandangan Casanova itu cenderung menerjemahkan sekularisasi dalam ihwal politik. Sedangkan sekularisasi dalam ihwal sosial benar-benar terjadi. Turner menyebutnya dengan istilah pietization. Pietization ini yang belakangan menjelma menjadi gaya hidup yang khas di kalangan kelas menengah ke atas. ${ }^{18}$ Tampilnya Jery Falwell atau yang belakangan muncul seperti Joel Oesteen yang menggantikan ayahnya di Lakewood Megachurch menunjukkan model baru praktik keagamaan di kalangan kelas menengah ke atas. Mereka lebih suka dengan agama yang dikemas melalui pesan-pesan motivasi daripada doktrin keagamaan yang tampak garang dan mengikat. ${ }^{19}$ Tampilnya Joel Oesteen yang lebih terlihat sebagai motivator dari pada seorang agamawan merupakan cara dia untuk menyuguhkan agama dengan kemasan yang lebih segar pasca runtuhnya wacana sekularisasi di Barat.

${ }^{16}$ José Casanova, Public Religions in the Modern World (Chicago: University of Chicago Press, 1994), 145-158; Susan Harding, The Book of Jerry Falwell: Fundamentalist Language and Politics (Princeton University Press, 2000), 17.

17 Casanova, "The Secular and Secularisms," 1049-66.

18 Bryan S. Turner, "Islam, Public Religions and the Secularization Debate," dalam Muslim Societies and the Challenge of Secularization: An Interdisciplinary Approach, ed. oleh Gabriele Marranci (New York: Springer, 2010), 12-14; Turner, "Islam, Public Religions and the Secularization Debate," 16.

${ }^{19}$ Mara Einstein, Brands of faith: marketing religion in a commercial age, Religion, media and culture series (London ; New York: Routledge, 2008), 120-46. 
Sebelum wacana sekularisasi mengemuka, agama menjadi kebutuhan masyarakat, artinya agama bersifat demand-side religion (permintaan). Namun, pasca wacana sekularisasi, utamanya ketika Barat tenggelam dalam arus industrialisasi dan modernisasi, agama berubah menjadi supply-side religion (ditawarkan). Karena agama harus disuplai, maka kemasan agama harus terlihat baru dan modern. Ini bertujuan untuk mengakomodasi semangat beragama pasca sekularisasi. Dalam konteks itulah, agamawan seperti Joel Oesteen menjadi relevan kemunculannya. Dia mengemas pesan keagamaan yang berbeda dengan ayahnya, John Oesteen.

Pengaruh globalisasi membuat wacana sekularisasi itu tidak hanya berlaku di ruang publik barat, tetapi pada gilirannya juga memengaruhi tradisi keagamaan di negara-negara lain termasuk Indonesia. Hadirnya ustaz-ustaz selebriti di Indonesia seperti halnya Joel Oesteen di Amerika, Amr Khaleed di Mesir ataupun Baba Ramdev di India. ${ }^{20}$ Selain itu, tradisi ngaji ke seorang guru agama atau sering disebut ustaz di majelis-majelis agama pada gilirannya berubah menjadi googling kiai, mencari sumber agama melalui internet. ${ }^{21}$ Wanita-wanita muda Islam Indonesia kini lebih suka memakai jilbab bermerek terkenal, yang dimaknai tidak hanya menunaikan kewajiban agama (kesalehan), tetapi juga ingin terlihat modis dan trendi. Mereka lebih suka mengonsumsi produk-produk Islam dan terjamin kehalalannya. Sebagian mereka juga memilih tempat tinggal atau perumahan-perumahan yang berbasis Islam (perumahan madani) dan berobat di klinik-klinik Islam. Beberapa ihwal tersebut menunjukkan bahwa sekularisasi pada gilirannya mengubah wajah agama menjadi cair dan dipraktikkan dalam gaya hidup baru yang berbeda dengan pendahulupendahulu mereka.

${ }^{20}$ Pradip Ninan Thomas dan Philip Lee, ed., Global and Local Televangelism (London: Palgrave Macmillan UK, 2012), 1-17, https://doi.org/10.1057/9781137264817.

${ }^{21}$ Lihat Nadirsyah Hosen, "Online Fatwa in Indonesia: From Fatwa Shopping to Googling a Kiai," dalam Expressing Islam: Religious Life and Politics in Indonesia, ed. oleh Greg Fealy dan White (Singapore: Institute of Southeast Asian Studies, 2008), 159-73.

88 | El Madani: Jurnal Dakwah dan Komunikasi Islam, Volume 1 No. 02 (2020) 
Pebisnis Islam dan Muslim Kelas Menengah ke Atas di Indonesia: Kesalehan, Gaya Hidup, dan Pasar

Muslim Kelas Menengah Ke atas dan Islam di Masa Orde Baru

Pasca runtuhnya Orde lama dan memasuki era baru yang dikenal dengan Orde Baru atau disingkat Orba memberikan harapan baru bagi Islam politik untuk menguatkan posisinya. Namun, pada kenyataannya kekuatan-kekuatan Islam politik justru menjadi lawan kekuasaan Soeharto. Karena disharmonitas tersebut, kelompok Muslim tidak dianggap dari bagian penting pertumbuhan kelas menengah pada saat itu. $^{22}$

Dalam perkembangannya, pasca kegagalan mengakomodasi kekuatan Islam dalam sistem politik negara, muncul kelas menengah baru yang tidak lagi berorientasi pada usaha menegakkan kekuatan Islam dalam sistem politik negara. Mereka adalah Muslim kelas menengah ke atas yang berasal dari keluarga santri. Mereka menikmati pendidikan menengah dan tinggi di sekolah-sekolah ataupun universitas-universitas modern. ${ }^{23}$ Berkat pengalaman menempuh pendidikan di sekolah-sekolah tinggi dan kampus-kampus modern membuat mobilitas santri semakin dekat dengan pemerintah.

Masuknya santri dalam birokrasi pemerintahan setidaknya membuat sikap pemerintahan Orba semakin melunak terhadap Islam. Presiden Soeharto mulai mengapresiasi Islam politik di Indonesia. Ini ditunjukkan dengan dukungan Soeharto terhadap pembentukan Ikatan Cendekiawan Muslim Indonesia (ICMI) dan Bank Islam pertama, Muamalah pada tahun 1990-an. ${ }^{24}$ Puncaknya, pada akhir tahun 1990an, seiring dengan melemahnya posisi rezim Orba di Indonesia, Soeharto semakin

22 Daniel S Lev, "Intermediate Classes and Change in Indonesia: Some Initial Reflections," dalam The Politics of middle class Indonesia, ed. oleh Richard Tanter dan Kenneth Ray Young (Clayton, Vic., Australia: Centre of Southeast Asian Studies, Monash University, 1990), 25-43; R. William Liddle, "The Middle Class and New Order Legitimacy: A Response to Dan Lev," dalam The Politics of middle class Indonesia, ed. oleh Richard Tanter dan Kenneth Ray Young (Clayton, Vic., Australia: Centre of Southeast Asian Studies, Monash University, 1990), 49-58.

${ }^{23}$ Abdurrahman Wahid, "Indonesia's Muslim Middle Class: An Imperative or a Choice?," dalam The Politics of middle class Indonesia, ed. oleh Richard Tanter dan Kenneth Ray Young (Clayton, Vic., Australia: Centre of Southeast Asian Studies, Monash University, 1990), $22-24$.

${ }^{24}$ Robert W. Hefner, "Islam, State, and Civil Society: ICMI and the Struggle for the Indonesian Middle Class," Indonesia 56 (Oktober 1993): 1-35, https://doi.org/10.2307/3351197. 
memberikan sambutan baik terhadap Islam di Indonesia. Dia mengakomodasi dukungan Muslim di Indonesia untuk menguatkan posisinya melalui berbagai cara seperti menunjukkan identitas kesalehannya dengan menunaikan ibadah haji ke Mekkah. Selain itu, dia juga menghapus larangan penggunaan jilbab di kalangan siswi sekolah. ${ }^{25}$ Pada saat yang bersamaan khotbah publik mulai bergema keras di sejumlah stadion di Indonesia.

Munculnya Muslim kelas menengah tentu tidak bisa dipisahkan dari program pembangunan di masa Orba. Pemerintah Orba berhasil menekan tingkat kesuburan perempuan melalui program Keluarga Berencana (KB). Melalui program ini, masyarakat Indonesia semakin menyadari pentingnya kesejahteraan dan pendidikan bagi putra-putri mereka. Memiliki sedikit anak merupakan salah satu cara untuk mewujudkannya. Selain itu, untuk menekan tingkat kemiskinan, pemerintah Orba mengenalkan program Jaring Pengaman Sosial. Orang-orang yang bekerja di perusahaan menengah, pemerintahan dan militer diberi akses terhadap jaminan kesehatan melalui tempat kerja mereka. ${ }^{26}$ Pemerintah juga secara masif membantu orang-orang miskin melalui bantuan langsung tunai, jaminan bahan pokok dan subsidi barang-barang kebutuhan pokok, serta menyediakan lapangan pekerjaan. ${ }^{27}$ Namun, apakah program-program ini efektif untuk menurunkan tingkat kemiskinan di masa itu ataukah tidak, tentu bukan di sini tempatnya untuk mendiskusikan hal itu. Ihwal ini pula yang kemudian belakangan menjadi cikal bakal munculnya lembaga-lembaga filantropi non-negara.

Selain pengaruh program-program pembangunan di era Orde Baru, pertumbuhan Muslim kelas menengah ke atas juga diinisiasi oleh gerakan revolusi Iran pada tahun 1979 dan ekspansi gerakan salafi yang mendedahkan Islam sebagai

\footnotetext{
${ }^{25}$ Nancy J. Smith-Hefner, “Javanese Women and the Veil in Post-Soeharto Indonesia," The Journal of Asian Studies 66, no. 2 (Mei 2007): 389-420, https://doi.org/10.1017/S0021911807000575.

${ }^{26}$ Minako Sakai, "Building a Partnership for Social Service Delivery in Indonesia: State and FaithBased Organisations," Australian Journal of Social Issues 47, no. 3 (September 2012): 375, https://doi.org/10.1002/j.1839-4655.2012.tb00254.x.

27 Anne Daly dan George Fane, "Anti-Poverty Programs in Indonesia," Bulletin of Indonesian Economic Studies 38, no. 3 (Desember 2002): 309, https://doi.org/10.1080/00074910215535.
} 
Pebisnis Islam dan Muslim Kelas Menengah ke Atas di Indonesia: Kesalehan, Gaya Hidup, dan Pasar satu-satunya referensi sekaligus solusi dalam kehidupan sehari-hari. Revolusi yang dipimpin oleh Ayatullah Khomeini sangat menginspirasi pemuda-pemuda Muslim di Indonesia. ${ }^{28}$ Sebagian dari mereka banyak yang melakukan kegiatan-kegiatan dakwah berbasis masjid yang dipelopori oleh aktivis masjid Salman ITB. Imaduddin Abdurrachim atau yang akrab disapa Kang Imad menjadi pelopor kegiatan dakwah tersebut. Salah satunya dia mempromosikan program Latihan Mujahid Dakwah (LMD). Dengan mendapatkan dukungan dari Muhammad Natsir, ketua Dewan Dakwah Islamiyah Indonesia (DDII), LMD berkembang pesat dan sangat diminati di kalangan anak muda Islam. ${ }^{29}$ Ihwal ini yang pada perkembangannya menjadi inspirasi bagi gerakan dakwah di kalangan anak muda Islam Indonesia.

Ekspansi gerakan Salafi juga menginspirasi pertumbuhan Muslim kelas menengah ke atas di Indonesia. Mereka mendengungkan semangat kembali kepada Alquran dan sunnah, utamanya di tengah pengaruh globalisasi dan modernisasi yang dipandang menggerus nilai-nilai keislaman baik dalam praktik berpakaian, sosial, hiburan bahkan sistem politik. Mereka menghembuskan slogan Islam adalah solusi satu-satunya dan mengajak Muslim untuk mengikuti jejak generasi awal Islam (Salaf al-Salih). ${ }^{30}$ Dalam perkembangannya, kelompok Salafi membangun masjid-masjid megah di tengah kota, mempromosikan pengobatan sunnah dan obat-obatan herbal yang menarik perhatian kelas menengah ke atas di Indonesia. ${ }^{31}$

Kini Muslim kelas menengah ke atas tidak hanya menghabiskan waktu mereka untuk mencari penghasilan ataupun mengembangkan karier, tetapi di saat yang

${ }^{28}$ Sidney R Jones, “'It Can't Happen Here': A Post Khomeini Look at Indonesian Islam,” Asian Survey XX, no. 3 (1980): 311-23.

${ }^{29}$ Rifki Rosyad, Quest for True Islam: A Study of the Islamic Resurgence Movement among the Youth in Bandung, Indonesia (Canberra, A.C.T.: ANU E Press, 2007), 27-34, http://public.eblib.com/choice/publicfullrecord.aspx? $\mathrm{p}=4749819$.

30 N. Hasan, "The Salafi Movement in Indonesia: Transnational Dynamics and Local Development," Comparative Studies of South Asia, Africa and the Middle East 27, no. 1 (1 Januari 2007): 8394, https://doi.org/10.1215/1089201x-2006-045.

${ }^{31}$ Dony arung Triantoro, Fathayatul Husna, and Afina Amna, "Ruqyah Syar'iyyah: Alternatif Pengobatan, Kesalehan, Islamisme Dan Pasar Islam," Harmoni 18, no. 1 (June 30, 2019): 460-78, https://doi.org/10.32488/harmoni.v18i1.354.

El Madani: Jurnal Dakwah dan Komunikasi Islam, Volume 1 No. 02 (2020) | 91 
bersamaan, mereka menggunakan waktu luang mereka untuk berbelanja santai di Mall-mall, mengikuti pengajian-pengajian keagamaan yang digelar di masjid-masjid megah maupun hotel-hotel berbintang lima. Fenomena kelas menengah ke atas di Indonesia sangat khas karena persentuhan mereka dengan simbol-simbol Islam dan budaya populer yang semakin mengemuka di ruang publik. Mereka secara terbuka mengekspresikan identitas keislaman mereka di ruang publik. ${ }^{32}$ Selain itu, munculnya Muslim kelas menengah ke atas di Indonesia sama seperti kelas menengah Asia yang menikmati ekspansi kapitalisme. Untuk mengetahui lebih jauh tentang bagaimana Muslim kelas menengah ke atas di Indonesia mengekspresikan identitas keislamannya, bagian berikutnya akan menjelaskan ihwal tersebut.

\section{Muslim Kelas Menengah Ke Atas: Kesalehan, Gaya Hidup dan Pasar}

Muslim kelas menengah ke atas yang identik dengan kemapanan ekonomi pada gilirannya mengarah pada pola konsumsi keseharian mereka yang khas. Pada bagian ini saya menunjukkan persimpangan antara kesalehan, gaya hidup dan pasar. Muslim kelas menengah ke atas yang sedang menikmati pola perilaku hidup Islam mengambil bentuk-bentuk ungkapan keagamaan yang berbeda dari pendahulupendahulu mereka. Di satu sisi, mereka menunjukkan identitas kesalehannya, tetapi di sisi lain ihwal ini menjadi gaya hidup dan menunjukkan kelas sosial mereka. Gaya hidup keagamaan baru yang diungkapkan Muslim kelas menengah ke atas pada gilirannya ditangkap oleh pasar, sehingga banyak aktor-aktor pebisnis Islam yang memproduksi dan mendistribusikan barang-barang Islam. Tidak jarang, antar aktor bisnis yang satu dengan yang lainnya saling berkompetisi, sehingga pada gilirannya dakwah mengalami gentrifikasi sesuai selera konsumen. ${ }^{33}$

Seperti yang telah saya sebutkan di awal tulisan ini bahwa Muslim kelas menengah ke atas banyak yang memiliki akses ke birokrasi pemerintahan, sehingga

32 Hasan, "The Making of Public Islam," 229-50.

${ }_{33}$ Mona Abaza, “Markets of Faith : Jakartan Da'wa and Islamic Gentrification," Archipel 67, no. 1 (2004): 173-202, https://doi.org/10.3406/arch.2004.3813.

92 | El Madani: Jurnal Dakwah dan Komunikasi Islam, Volume 1 No. 02 (2020) 
Pebisnis Islam dan Muslim Kelas Menengah ke Atas di Indonesia: Kesalehan, Gaya Hidup, dan Pasar ihwal ini membuat sejumlah perkantoran berlomba-lomba untuk mendirikan Musala dan Masjid. Tidak jarang, di masjid-masjid tersebut digelar kegiatan-kegiatan keagamaan. Sebagai contoh, Masjid Muthmainnah Polda Riau, misalnya, di masjid ini sering digelar kajian-kajian keagamaan yang diinisiasi oleh remaja masjid Muthmainnah atau yang dikenal Forum Silaturrahim Remaja Masjid Muthmainnah (FSRMM). Selain kantor-kantor pemerintahan, kampus-kampus negeri maupun swasta juga berlomba-lomba mendirikan masjid kampus. Tidak ketinggalan, pusatpusat perbelanjaan seperti Mall juga menyediakan ruang-ruang Salat. Mall di Yogyakarta yang saya kunjungi pada umumnya menyediakan ruang-ruang Salat. Lippo Plaza dan Hartono Mall adalah beberapa contohnya.

Di luar kantor dan Mall, semangat keislaman mereka ditampung oleh aktoraktor keagamaan baru yang menyediakan produk-produk Islam. Ustaz Hanan Attaki, seorang pengkhotbah populer asal Bandung, misalnya, dia menawarkan acara-acara pengajian berbayar mahal yang diadakan di hotel-hotel berbintang lima. Dia tampil layaknya anak muda perkotaan dengan balutan produk-produk distro seperti kemeja flannel dan kupluk. ${ }^{34}$ Selain itu, dia mengemas pesan dakwahnya dengan bahasabahasa gaul atau penuturan kisah (storytelling). Konsep seperti ini sebenarnya telah lebih dulu dilakukan oleh Aa Gym dengan program training manajemen qalbunya (MQ). ${ }^{35}$ Di luar kegiatan berceramahnya, Ustaz Hanan sering beraktivitas layaknya anak muda perkotaan seperti bermain skateboard dan sepatu roda.

\footnotetext{
${ }^{34}$ Muhamad Ibtissam Han, Dakwah Jalanan Kaum Muda: Dinamika Keagamaan Anak Muda Genk Motor dan Skateboard (Yogyakarta: Diandra Kreatif dan Penerbit Omah ilmu, 2019), 35.

${ }^{35}$ James B Hoesterey, "Marketing Morality: The Rise, Fall and Rebranding of AA Gym," dalam Expressing Islam: Religious Life and Politics in Indonesia, ed. oleh Greg Feally dan White Sally (Singapore: Institute of Southeast Asian Studies, 2008), 95-112.
} 


\section{Gambar 1}

\section{Poster Pengajian Ustaz Hanan Attaki}
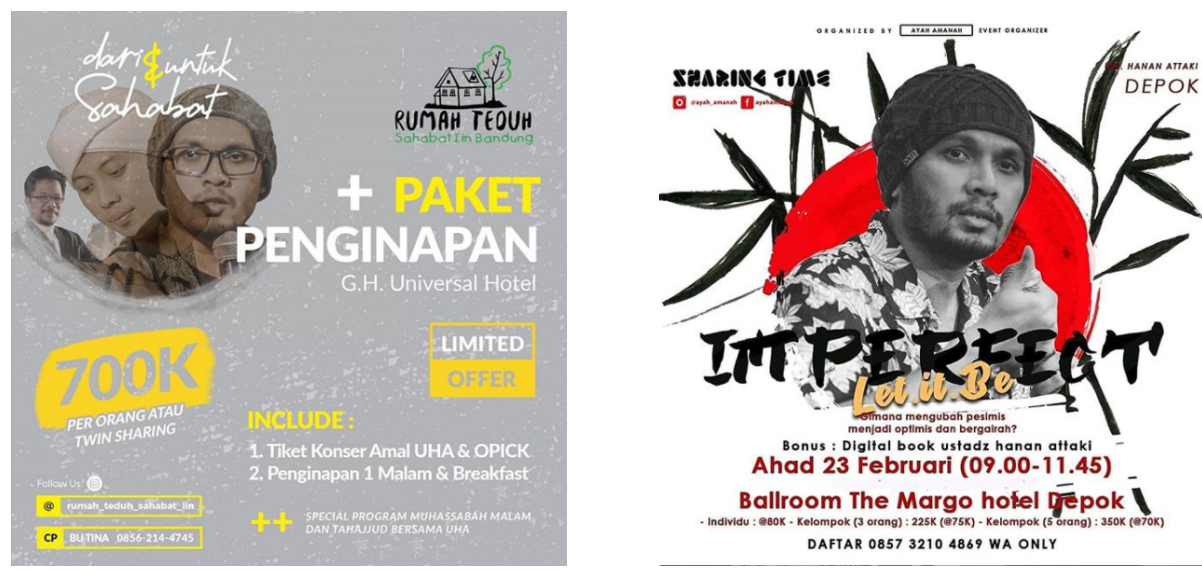

Sumber:

https://www.instagram.com/p/BpG2VpenlGY/?utm source=ig web copy link dan https://www.instagram.com/p/B8vc1vYhP0O/?utm_source=ig_web_copy_link

Selain Ustaz Hanan, Ustaz Evie Effendy adalah contoh lain dari pengkhotbah popular asal Bandung. Dia tampil memesona kalangan anak muda Islam dengan diksi-diksi populernya, dear mantan maafkan aku yang dulu atau singkatan lainnya seperti gapleh (gaul tapi sholeh). ${ }^{36}$ Seperti halnya Ustaz Hanan, Ustaz Evie tidak mengenakan baju koko dan surban seperti ustaz pada umumnya. Dia menggunakan kaos, kemeja, switer dan kupluk. Namun, Ustaz Evie berbeda dengan Ustaz Hanan. Ustaz Evie tidak memiliki jalur pendidikan agama Islam formal yang kuat seperti halnya Ustaz Hanan yang merupakan lulusan Al-Azhar, Kairo, Mesir. ${ }^{37}$

Dalam kehidupan sehari-hari, Muslim kelas menengah ke atas juga mempraktikkan gaya hidup mereka dengan mengonsumsi produk-produk Islam. Dalam model berpakaian, misalnya, perempuan-perempuan muda Muslim kelas menengah ke atas lebih menyukai menggunakan mode berpakaian yang syar'i namun tetap tampil modis. Ihwal ini bisa dilihat dari kemunculan komunitas hijabers (hijabers

\footnotetext{
36 Muhamad Ibtissam Han, “Ustadz Hits: Bahasa Gaul dan Social Media Effect," dalam Islam: Antara Teks, Kuasa dan Identitas, ed. oleh Sunarwoto (Yogyakarta: Arti Bumi Intaran, 2018), 175.

${ }_{37}$ Han, Dakwah Jalanan Kaum Muda: Dinamika Keagamaan Anak Muda Genk Motor dan Skateboard, 68.
}

94 | El Madani: Jurnal Dakwah dan Komunikasi Islam, Volume 1 No. 02 (2020) 
Pebisnis Islam dan Muslim Kelas Menengah ke Atas di Indonesia: Kesalehan, Gaya Hidup, dan Pasar community) yang digawangi oleh Dian Pelangi dan teman-temannya. Hijabers Community yang disingkat HC merupakan kumpulan wanita-wanita Muslim kelas menengah ke atas yang mendengungkan tentang pentingnya menggunakan hijab sekaligus mengenalkan model hijab popular. Popularitas HC juga bersamaan dengan menjamurnya toko-toko butik dan fashion Islam di Indonesia. Melalui HC kita bisa melihat bagaimana wanita Muslim pada satu sisi ingin menampilkan kesalehannya dalam menggunakan hijab, tetapi pada sisi yang lain, mereka ingin tetap tampil modis dan keren. Selain itu, brand-brand hijab yang mereka gunakan juga menunjukkan kelas sosial mereka sebagai bagian dari Muslim kelas menengah ke atas. Salah satu toko butik Islam yang saya kunjungi di Pekanbaru yaitu Rabbani merupakan salah satu brand pakaian Muslim yang sangat terkenal di Indonesia. Rabbani yang dipromosikan oleh penceramah popular Indonesia, Ustaz Sholeh Mahmud atau yang akrab dipanggil Ustaz Sholmed, menyediakan berbagai bentuk fashion Islam terkini dengan harga yang mahal.

Mempromosikan gaya berpakaian yang syar'i dan sesuai sunnah juga menjadi cara mereka untuk mendapatkan konsumen. Salah satu toko pakaian Islam yang saya kunjungi pada bulan Juli 2020 di Mall Metro Trade Center Giant Panam, Rara Hijab adalah contoh bagaimana mereka mempromosikan gaya pakaian mereka yang sesuai sunnah. Rara Hijab, selain menjual model pakaian-pakaian Islam pada umumnya, mereka juga menjual pakaian-pakaian khas Islam Puritan seperti Salafi. Di bagian pintu masuknya, mereka memasang contoh pakaian-pakaian Salafi seperti niqab, jubah, dan jilbab panjang. Selain itu, para karyawannya sebagian besar menggunakan niqab. Mereka juga menyebut pakaian pria dengan sebutan pakaian ikhwan dan pakaian akhwat untuk menyebut pakaian wanita. Ini menunjukkan bahwa pasar Islam tidak bersifat netral, melainkan ada kepentingan pasar dan ideologi Islam tertentu. Beberapa contoh toko pakaian Islam tersebut menunjukkan bahwa seiring dengan meningkatnya ekspresi keislaman di kalangan Muslim kelas menengah ke 
atas pada saat yang bersamaan ekspresi itu ditampung oleh aktor-aktor pebisnis Islam yang menyediakan produk-produk kebutuhan mereka.

Tren syar'i baru-baru ini tidak hanya digunakan untuk mempromosikan model berpakaian Islam saja, tetapi juga perumahan-perumahan Islam, hotel Islam, dan layanan Catering Islam. Dalam akun Instagram @perumahanislamiindonesia, misalnya, mereka menawarkan perumahan-perumahan syariah. Mereka berpendapat bahwa proses perdagangannya mengutamakan aspek kejujuran dan amanah, bahkan mereka menguatkan pendapatnya dengan mengutip hadis nabi dari Abdulloh bin Umar yang menyebutkan: "Seorang pedagang Muslim yang jujur dan amanah (terpercaya) akan (dikumpulkan) bersama para nabi, orang-orang shiddiq dan orang-orang yang mati syahid pada hari kiamat (nanti)." Selain itu, mereka menjelaskan mengapa Muslim harus memilih perumahan Islami. Menurut mereka bahwa dalam proses penjualannya, perumahan Islami menggunakan system syariah yaitu tanpa riba, tanpa bank, tanpa bunga, tanpa denda, tanpa sita, tanpa akad bathil dan hidup lebih tenteram. ${ }^{38}$

Seperti halnya perumahan Islami, pada saat yang bersamaan muncul juga hotel-hotel berbasis syariah seperti Syariah Hotel Solo yang terletak di Jl. Adi Sucipto 47, Surakarta, Ibrahim Hotel Syariah di Semarang, Hotel Zaira Pekanbaru, Hotel Syariah Sri Indrayani Pekanbaru, Hotel Rauda Pekanbaru, dan bahkan Hotel berkonsep halal seperti Hotel Pesonna di Pekanbaru. Terakhir konsep syar'i juga digunakan oleh aktor-aktor bisnis catering. ${ }^{39}$ Gerak Mulia Aqiqah adalah salah satu contoh bisnis catering yang mengonsep bisnisnya dengan motto syar'i, amanah dan praktis. Mereka secara masif mempromosikan jasa catering untuk aqiqah. Mereka membangun argumen tentang konsep syar'i yang mereka usung. Menurut mereka bahwa jasa catering aqiqah mereka menggunakan hewan yang memenuhi syarat sah untuk aqiqah. Kemudian hasil olahan masakan mereka menggunakan rempah dan

\footnotetext{
${ }^{38}$ Lihat http://www.perumahanislamiindonesia.com/ (Diakses pada 9 agustus 2020, pukul 11.40 Wib).

${ }^{39}$ Catering adalah jasa atau bisnis yang bergerak dalam bidang kuliner. Mereka menyediakan dan menyajikan makanan dan minuman untuk umum sesuai permintaan (pesanan) konsumen atau pelanggan.
}

96 | El Madani: Jurnal Dakwah dan Komunikasi Islam, Volume 1 No. 02 (2020) 
Pebisnis Islam dan Muslim Kelas Menengah ke Atas di Indonesia: Kesalehan, Gaya Hidup, dan Pasar bumbu-bumbu pilihan. Mereka tidak menggabungkan daging hewan aqiqah sohibul aqiqah yang satu dengan shohibul aqiqah lainnya. Mereka menjaga kualitas pelayanan dan rasa masakan karena menyangkut amanah dan kewajiban mutlak mereka. Ini menunjukkan bagaimana aktor-aktor bisnis Islam memfasilitasi kebutuhan Muslim kelas menengah ke atas yang tidak banyak memiliki waktu luang dan lebih banyak meghabiskan waktu di kantor atau tempat-tempat bekerja lainnya.

\section{Gambar 2}

\section{Poster Gerak Mulia Aqiqah}

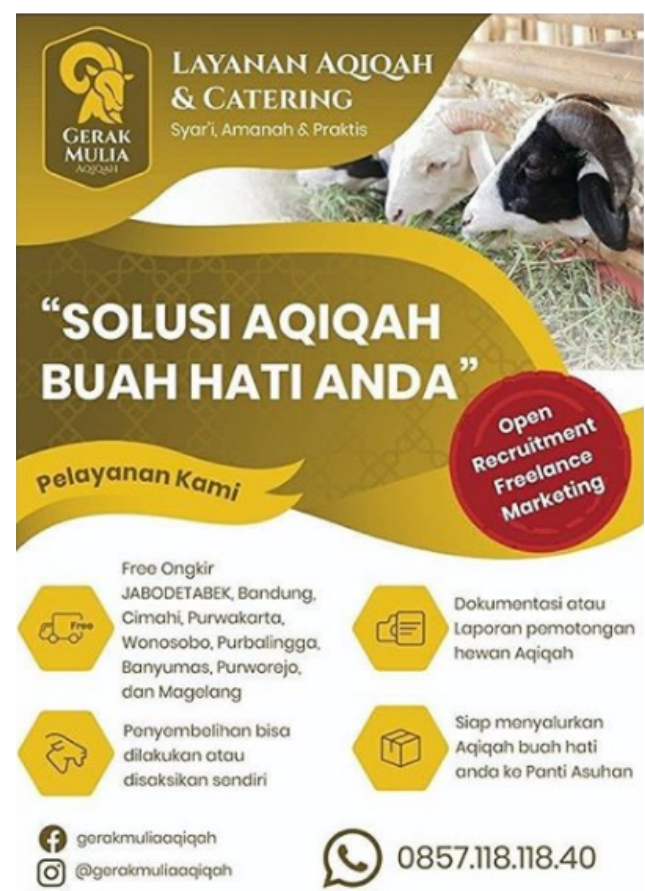

Sumber: https://www.instagram.com/p/CEQTr4MhDz_/?utm_source=ig_web_copy_link

Selain tren syar'i, tren halal juga mengelilingi kehidupan Muslim kelas menengah ke atas. Ini termasuk pengembangan konsep hijrah yang sering didengungkan oleh kalangan Tarbiyah. Hijrah dalam perkembangannya tidak hanya ditujukan pada pergerakan Nabi Muhammad dari Mekkah ke Madinah, tetapi juga perpindahan dari barang-barang yang dianggap sekuler ke barang-barang yang diklaim Islami atau halal. Semisal, munculnya make up halal, kulkas halal, mesin cuci hijab, halal tourism, halal mart, shampo hijab, dan lainnya. Saya banyak menemui barang-barang rumah tangga tersebut di toko-toko ataupun swalayan di Pekanbaru. 
Ketika saya mengunjungi salah satu toko perabotan rumah tangga di Pekanbaru yang dimiliki oleh seorang beretnis Tionghoa, saya melihat mereka menjual kulkas halal dan mesin cuci hijab. Mereka mempromosikan perabotan rumah tangga itu dengan menjelaskan kelebihan-kelebihannya, sehingga akhirnya saudara perempuan (kakak) saya membeli kulkas dan mesin cuci yang memiliki tendensi Islami itu. Ini menunjukkan bahwa aktor-aktor bisnis Islam pada gilirannya tidak hanya diisi oleh orang-orang Muslim saja, tetapi juga orang-orang di luar Muslim. Ihwal ini merupakan konsekuensi dari sifat pasar bebas yang para aktornya saling berkompetisi untuk merebut pangsa pasar. Selain itu, fenomena ini juga menunjukkan bahwa konsep halal pada perkembangannya mengalami fragmentasi. Status halal tidak lagi diklaim kuat untuk menyatakan keamanan (kehalalan) sebuah produk makanan, tetapi juga barang-barang konsumsi lainnya seperti kulkas, mesin cuci dan lainnya.

Aktor-aktor pebisnis Islam membangun brand-brand usaha mereka dengan simbol-simbol yang diinisiasikan dengan Islam dan bahkan menggabungkannya dengan simbol-simbol di luar Islam. Sebagai contohnya, di Pekanbaru ada usaha kuliner yang diberi nama Labbaik Chicken. Layaknya KFC, CFC dan sejenisnya, Labbaik Chicken juga menjual menu ayam goreng dan menu lainnya dengan mengusung brand Islam. Lebih dari itu, Labbaik Chicken menggabungkan dua term yang berbeda dalam brandnya. Labbaik adalah term yang diinisiasi dengan Islam yang artinya kami datang, sedangkan Chicken adalah term bahasa Inggris yang artinya ayam. Ini menunjukkan bahwa pebisnis Islam dalam satu sisi ingin mengakomodir pola konsumsi baru di kalangan Muslim kelas menengah yang mulai suka menggunakan produk-produk Islam, tetapi pada sisi lain, mereka ingin menguasai pasar dengan menggandeng simbol-simbol kuliner yang telah mapan seperti KFC, CFC dan sejenisnya. Terkait penggunaan nama ini, seorang Warganet di media sosial menganggap bahwa hal ini sebagai bentuk penghinaan terhadap Islam. Mereka berargumen bahwa kata Labbaik yang artinya aku penuhi panggilanmu adalah panggilan yang sering digunakan untuk memenuhi panggilan haji, sedangkan 98 | El Madani: Jurnal Dakwah dan Komunikasi Islam, Volume 1 No. 02 (2020) 
Pebisnis Islam dan Muslim Kelas Menengah ke Atas di Indonesia: Kesalehan, Gaya Hidup, dan Pasar Labbaik Chicken berarti aku penuhi panggilanmu ayam. Terkait ini, pihak Labbaik Chicken menjelaskan bahwa Labbaik yang artinya kami datang memiliki makna bahwa kami datang ke seluruh pelosok negeri untuk memenuhi kebutuhan masyarakat akan produk halal. Sedangkan kata Chicken untuk menunjukkan identitas usahanya. Meskipun demikian, Labbaik Chicken telah menyebar ke berbagai daerah di Indonesia seperti Bandung, Banten, Cimahi, Sukabumi, Bengkulu, Bogor dan daerah lainnya.

Berbeda dengan Labbaik Chicken yang tendensi Islamnya sangat mencolok pada brand namanya, salah satu warung makan yang saya kunjungi di Yogyakarta, Warung Preksu (Geprek Susu) memiliki tendensi Islam pada aktivitas karyawannya dan program pemasarannya. Ketika saya mengunjungi Preksu beberapa kali, saya mengamati para pelayan menggunakan simbol-simbol Islam. Semisal, untuk yang laki-laki, mereka pada umumnya menggunakan peci, sedangkan untuk yang perempuan, mereka menggunakan jilbab bahkan sebagian menggunakan niqab. Ketika waktu salat, mereka tidak membuka pelayanan. Mereka semua melakukan salat berjamaah di Musala warung Preksu. Terkait program pemasarannya, Preksu memberikan sejumlah porsi makanan gratis untuk pengunjungnya yang sedang berpuasa Senin-Kamis dan hafal sejumlah surah di dalam Alquran. Selain itu, Preksu juga secara masif menggelar pengajian-pengajian untuk karyawannya. Fenomena ini menunjukkan bahwa aktor bisnis Islam mengemas produk-produk mereka dengan artikulasi keislaman yang berbeda-beda.

\section{Kesimpulan}

Tulisan ini telah menunjukkan wacana yang menginisiasi kemunculan Muslim kelas menengah ke atas di Indonesia dan ekspresi-ekspresi gaya hidup Islam yang mereka tampilkan. Setidaknya ada tiga wacana yang mempengaruhi kemunculan Muslim kelas menengah ke atas di Indonesia yaitu Pertama, wacana sekularisasi, kedua, program pembangunan di era Orde Baru, dan terakhir semangat gerakan 
kebangkitan Islam. Terkait ekspresi gaya hidup Islam yang ditampilkan oleh Muslim kelas menengah ke atas sangat beragam. Muslim kelas menengah ke atas menampilkan kesalehan dan gaya hidup Islam mereka dengan mengonsumsi barangbarang Islam seperti mengenakan pakaian-pakaian Islam dan trendi, mengikuti pengajian berbayar mahal, menikmati waktu luang mereka dengan berjalan-jalan di Mall dan lainnya, menginginkan tinggal di perumahan-perumahan Islami, dan menggunakan barang-barang properti rumah tangga yang bertendensi Islami. Ekspresi-ekspresi gaya hidup Islam yang ditampilkan Muslim kelas menengah ke atas tersebut diapresiasi oleh aktor-aktor bisnis Islam yang menyediakan kebutuhankebutuhan Muslim kelas menengah ke atas.

\section{Saran}

Tulisan ini hanya menampilkan fenomena-fenomena umum dan bahkan mengkajinya secara umum, sehingga banyak detail-detail kecil yang belum tersentuh terkait negosiasi Muslim kelas menengah ke atas di Indonesia dalam mengekspresikan gaya hidup Islam baru mereka. Oleh karena itu, saya merekomendasikan untuk penelitian berikutnya agar memperdalam topik penelitian ini dalam ruang lingkup yang lebih spesifik. Tujuannya, agar mendapatkan data yang mendalam dan tuntas. Untuk mendapatkan data yang mendalam tentu saja tidak hanya menggunakan metode pengamatan seperti yang saya lakukan, tetapi juga melengkapinya dengan komunikasi pribadi (wawancara) kepada Muslim kelas menengah ke atas di Indonesia.

\section{Daftar Pustaka}

Abaza, Mona. "Markets of Faith : Jakartan Da'wa and Islamic Gentrification." Archipel 67, no. 1 (2004): 173-202. https://doi.org/10.3406/arch.2004.3813.

Campbell, Heidi, ed. Digital religion: understanding religious practice in new media worlds. Abingdon, Oxon ; New York: Routledge, 2012.

Casanova, José. Public religions in the modern world. Chicago: University of Chicago Press, 1994. 
Pebisnis Islam dan Muslim Kelas Menengah ke Atas di Indonesia: Kesalehan, Gaya Hidup, dan Pasar

Casanova, Jose. “The Secular and Secularisms.” social research 76, no. 4 (2009): 104966.

Daly, Anne, dan George Fane. "Anti-Poverty Programs in Indonesia." Bulletin of Indonesian Economic Studies 38, no. 3 (Desember 2002): 309-29. https://doi.org/10.1080/00074910215535.

Einstein, Mara. Brands of faith: marketing religion in a commercial age. Religion, media and culture series. London; New York: Routledge, 2008.

Han, Muhamad Ibtissam. Dakwah Jalanan Kaum Muda: Dinamika Keagamaan Anak Muda Genk Motor dan Skateboard. Yogyakarta: Diandra Kreatif dan Penerbit Omah ilmu, 2019.

- - - "Ustadz Hits: Bahasa Gaul dan Social Media Effect." Dalam Islam: Antara Teks, Kuasa dan Identitas, disunting oleh Sunarwoto, 163-81. Yogyakarta: Arti Bumi Intaran, 2018.

Harding, Susan. The Book of Jerry Falwell: Fundamentalist Language and Politics. Princeton University Press, 2000.

Hasan, N. "The Salafi Movement in Indonesia: Transnational Dynamics and Local Development." Comparative Studies of South Asia, Africa and the Middle East 27, no. 1 (1 Januari 2007): 83-94. https://doi.org/10.1215/1089201x-2006-045.

Hasan, Noorhaidi. "The Making of Public Islam: Piety, Agency, and Commodification on the Landscape of the Indonesian Public Sphere." Contemporary Islam 3, no. 3 (Oktober 2009): 229-50. https://doi.org/10.1007/s11562-009-0096-9.

Hefner, Robert W. "Islam, State, and Civil Society: ICMI and the Struggle for the Indonesian Middle Class." Indonesia 56 (Oktober 1993): 1. https://doi.org/10.2307/3351197.

Heryanto, Ariel. "The years of living luxuriously Identity politics of Indonesia's new rich." Dalam Culture and Privilege in Capitalist Asia, disunting oleh Michael Pinches, 160-87. London and New York: Routledge, 1999.

Hill, Hal. "The Economy." Dalam Indonesia's New Order: The Dynamics of SocioEconomic Transformation, disunting oleh Hal Hill, 54-122. Honolulu: University of Hawaii Press, 1994.

Hoesterey, James B. "Marketing Morality: The Rise, Fall and Rebranding of AA Gym." Dalam Expressing Islam: Religious Life and Politics in Indonesia, disunting oleh Greg Feally dan White Sally, 95-112. Singapore: Institute of Southeast Asian Studies, 2008.

Hosen, Nadirsyah. "Online Fatwa in Indonesia: From Fatwa Shopping to Googling a Kiai." Dalam Expressing Islam: Religious Life and Politics in Indonesia, disunting oleh Greg Fealy dan White, 159-73. Singapore: Institute of Southeast Asian Studies, 2008.

Huat, Chua Beng, dan Tan Joo Ean. "Singapore: Where the new middle class sets the standard." Dalam Culture and Privilege in Capitalist Asia, disunting oleh Michael Pinches, 138-59. London and New York: Routledge, 1999. 
Husna, Asmaul. “Komodifikasi Agama: Pergeseran Praktik Bisnis dan Kemunculan Kelas Menengah Muslim." Jurnal Komunikasi Global 7, no. 2 (2018): 227-39.

Jati, Wasisto Raharjo. "Memaknai Kelas Menangah Muslim sebagai Agen Perubahan Sosial Politik Indonesia." At-Tahrir 16, no. 1 (2016): 133-51.

Jones, Sidney R. "“It Can't Happen Here': A Post Khomeini Look at Indonesian Islam.” Asian Survey XX, no. 3 (1980): 311-23.

Lev, Daniel S. "Intermediate Classes and Change in Indonesia: Some Initial Reflections." Dalam The Politics of middle class Indonesia, disunting oleh Richard Tanter dan Kenneth Ray Young, 25-43. Clayton, Vic., Australia: Centre of Southeast Asian Studies, Monash University, 1990.

Liddle, R. William. "The Middle Class and New Order Legitimacy: A Response to Dan Lev." Dalam The Politics of middle class Indonesia, disunting oleh Richard Tanter dan Kenneth Ray Young, 49-58. Clayton, Vic., Australia: Centre of Southeast Asian Studies, Monash University, 1990.

Norris, Pippa, dan Ronald Inglehart. Sacred and secular: religion and politics worldwide. 2nd ed. Cambridge studies in social theory, religion and politics. Cambridge: Cambridge University Press, 2011.

Rakhmani, Inaya. Mainstreaming Islam in Indonesia: television, identity, and the middle class. New York, NY: Palgrave Macmillan, 2016.

Robison, Richard. "The middle class and the bourgeoisie in Indonesia." Dalam The New Rich in Asia: Mobile phones, McDonald's and middle-class revolution, disunting oleh Richard Robison dan David S. G. Goodman, 74-104. New York: Routledge, 1996.

Rosyad, Rifki. Quest for True Islam: A Study of the Islamic Resurgence Movement among the Youth in Bandung, Indonesia. Canberra, A.C.T.: ANU E Press, 2007. http://public.eblib.com/choice/publicfullrecord.aspx? $p=4749819$.

Sakai, Minako. "Building a Partnership for Social Service Delivery in Indonesia: State and Faith-Based Organisations." Australian Journal of Social Issues 47, no. 3 (September 2012): 373-88. https://doi.org/10.1002/j.1839-4655.2012.tb00254.x.

Smith-Hefner, Nancy J. "Javanese Women and the Veil in Post-Soeharto Indonesia." The Journal of Asian Studies 66, no. 2 (Mei 2007): 389-420. https://doi.org/10.1017/S0021911807000575.

- - - . "Satan in the Mall: Leisure and Consumption in Java's New Muslim Middle Class." Dalam Testing the Margins of Leisure Case Studies on China, Japan, and Indonesia, disunting oleh Rudolf G Wagner, Catherine Vance Yeh, Eugenio Menegon, dan Robert P Weller, 153-80. German: Heidelberg University Publishing, 2020. https://doi.org/10.17885/heiup.550.

Thomas, Pradip Ninan, dan Philip Lee, ed. Global and Local Televangelism. London: Palgrave Macmillan UK, 2012. https://doi.org/10.1057/9781137264817.

Triantoro, Dony arung, Fathayatul Husna, dan Amna. "Ruqyah Syar'iyyah: Alternatif Pengobatan, Kesalehan, Islamisme dan Pasar Islam." Harmoni 18, no. 1 (30 Juni 2019): 460-78. https://doi.org/10.32488/harmoni.v18i1.354. 

Kesalehan, Gaya Hidup, dan Pasar

Turner, Bryan S. "Islam, Public Religions and the Secularization Debate." Dalam Muslim Societies and the Challenge of Secularization: An Interdisciplinary Approach, disunting oleh Gabriele Marranci, 11-30. New York: Springer, 2010.

Wahid, Abdurrahman. "Indonesia's Muslim Middle Class: An Imperative or a Choice?" Dalam The Politics of middle class Indonesia, disunting oleh Richard Tanter dan Kenneth Ray Young, 22-24. Clayton, Vic., Australia: Centre of Southeast Asian Studies, Monash University, 1990.

Wilson, Bryan R. Religion in secular society: fifty years on. Disunting oleh Bruce. Reissue edition. Oxford, United Kingdom: Oxford University Press, 2016. 
Dony Arung Triantoro

104 | El Madani: Jurnal Dakwah dan Komunikasi Islam, Volume 1 No. 02 (2020) 